\title{
Seeing Polaris: A Call to Integrate Visual Images into Coaching Action Plans
}

\author{
Yaron Prywes \\ New York, USA \\ Elisabeth Mah \\ New York, USA
}

\begin{abstract}
This paper recommends that coaches consider equipping clients with a visual image to refer to between sessions. This recommendation is based on the authors' personal experience as well as research and theory from the fields of education, persuasion science, and motivational psychology, which suggest that visual images may help clients learn complex new behaviors and enhance motivation for goal pursuit. The authors identify the components of an integrative approach (visualtext hybrid) called "Polaris" and present a case study to provide coaches with the information needed to adopt this tool for their own practice. The paper concludes with implications for coaching researchers, coaching supervisors and coach educators.
\end{abstract}

Keywords: visual images, coaching plan, visual-text hybrid, Polaris.

\section{Less Mental Effort: A Picture is Worth a Thousand Words}

When it comes to action-planning efforts with clients, coaches would likely benefit from applying this adage literally. A typical "text-heavy" action plan is presented below (see Figure 1).

The details of the action plan are unimportant. The main takeaway to notice is that the plan is comprised predominantly of text, and although it contains a table to help organize the information into columns and rows, it is challenging for the reader to quickly extract the essence of the plan. 
Leadership Strengths: What strengths differentiate you in achieving your leadership imperative? How do you know?

\section{Courageous Under Pressure}

- Highest rated competence by all raters including direct manager, former managers, peers and reports $(4.5 / 5.0$ average)

- The question "Will not change her point of view just to please others" received the highest scores among all raters (4.7 / 5.0)

\section{Strong Networker}

- Cross-functional influence and ownership received high scores by peers, former managers, and direct manager (4.3/5.0)

- The question "Possesses the network of contacts necessary to get things done" received high marks (4.5 / 5.0 average), particularly from Former Managers (4.8) 5.0).
Leadership Development Areas: What areas do you need to work on to take your leadership to "the next level"? How do you know?

\section{Empower Others More}

- The feedback report clearly indicates that I need to do a better job empowering others (3.0 / 5.0 direct reports)

- Multiple raters made statements similar to the following: "Anne's leadership approach has unintended consequences - we go to her for everything big and small"

- Essentially, I need to delegate more. This will allow backoffice teams to experience more autonomy in their routines, and ultimately develop more capacity and independence.

\section{Criticize Self and Others Less}

- In 3 out of 6 competences on 360 my self-scores were significantly below the average ( 15 out of 30 questions). In other words, l'm a hard grader, relative to others. My coach shared with me that effective leadership is correlated with "slight modesty effect" -so this is something I need to pay attention to.

- The personality assessment also confirms my tendency to set high and sometimes unrealistic performance standards for myself (as well as my team and peers)

\begin{tabular}{|c|c|c|}
\hline VISION & $\begin{array}{l}\text { What is my vision? } \\
\text { What do I want to be known for as a leader? }\end{array}$ & $\begin{array}{l}\text { - To be recognized as a developer of high performance teams } \\
\text { - To be an inspirational leader, someone people want to work with }\end{array}$ \\
\hline $\begin{array}{l}\text { DEVELOPMENT } \\
\text { GOALS }\end{array}$ & $\begin{array}{l}\text { What are the development goals that will } \\
\text { support you achieving your VISION? } \\
\text { What is a barrier you need to address in } \\
\text { order to achieve this goal? }\end{array}$ & $\begin{array}{l}\text { - Empower my team so they can achieve their objectives more on } \\
\text { their own } \\
\text { - Barrier: My tendency to harshly criticize others (and self) }\end{array}$ \\
\hline $\begin{array}{l}\text { ACTION } \\
\text { STRATEGIES }\end{array}$ & $\begin{array}{l}\text { What behaviors are on my to-do / not to-do } \\
\text { list? }\end{array}$ & $\begin{array}{ll}\text { - } & \text { Establish projects that give direct reports more visibility and } \\
& \text { autonomy } \\
\text { - } & \text { Delegate more to field managers } \\
\text { - } & \text { Facilitate discussions, rather than drive (be less directive) } \\
\text { - } & \text { Ask others for solutions, before offering my own } \\
\text { - } & \text { Slow down, to allow for more thorough situational analysis }\end{array}$ \\
\hline EVIDENCE & $\begin{array}{l}\text { How will I and others know that I have } \\
\text { succeeded? }\end{array}$ & $\begin{array}{ll}\text { - } & \text { I will ask for feedback along the way } \\
\text { - } & \text { Others will feel less controlled and a greater sense of autonomy } \\
\text { - } & \text { Team performance will be less dependent on me }\end{array}$ \\
\hline QUESTIONS & $\begin{array}{l}\text { What support do I need? } \\
\text { What challenges do I face? } \\
\text { What questions do I now have? }\end{array}$ & $\begin{array}{ll}\text { - } & 3 \text { of } 8 \text { direct reports are new } \\
\text { - } & \text { Feedback from those around me, to make sure I am on track } \\
\text { - } & \text { How much latitude can the business afford to give people to } \\
& \text { develop? }\end{array}$ \\
\hline
\end{tabular}

\section{Figure 1: Sample two-page action plan}


In contrast, consider the following image:

\section{We are Visually Wired}

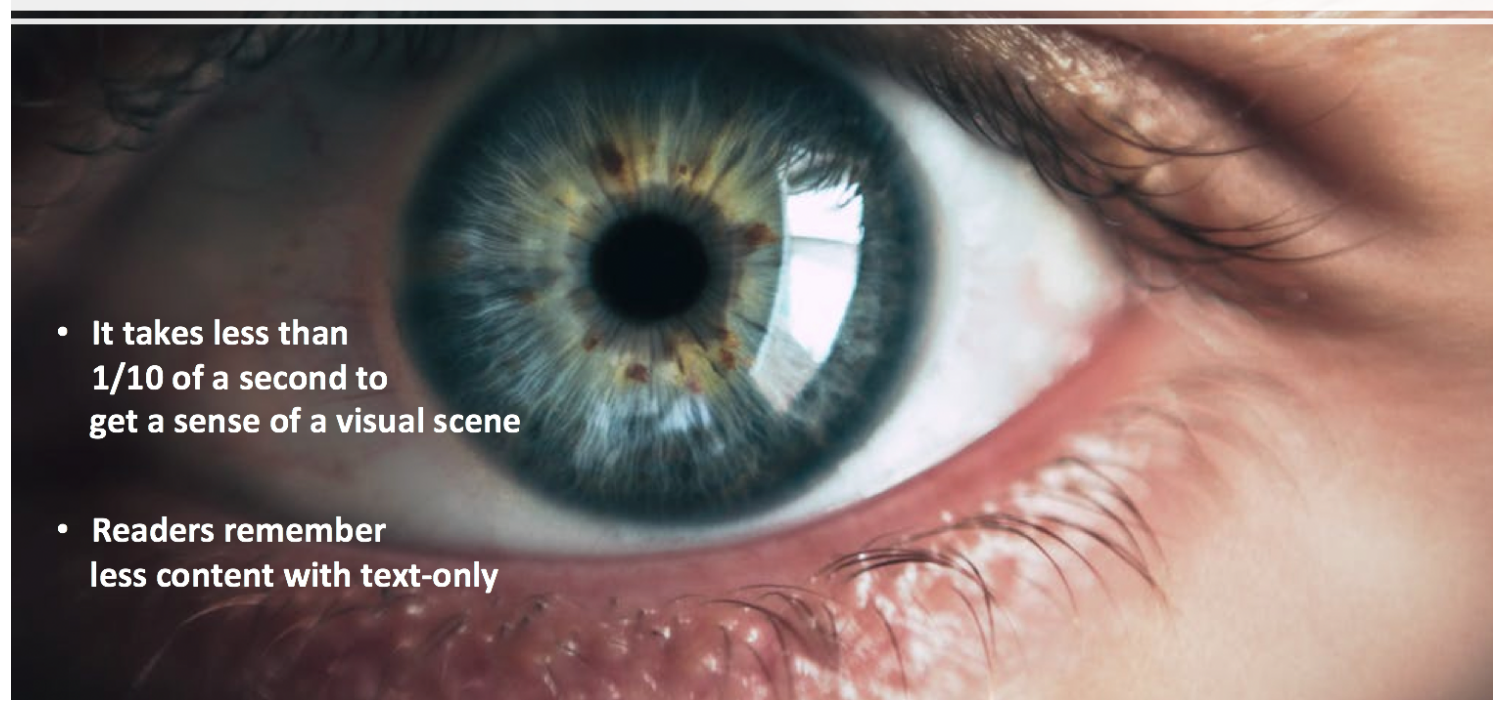

Figure 2: Display integrating visual and textual information. Digital Photo by Victor Freitas.

Research has shown that it takes less mental effort to interpret a visual representation of information than to read this same information conveyed via text (Hooijdonk \& Krahmer, 2008; Mayer \& Gallini, 1990). In other words, it is easier for your eyes to gaze and scan the information in Figure 2 above than it would be for you to read the information presented strictly with words. The reason is because text-only material contains abstract linguistic information that requires effortful processing. It also relies on the activation and retrieval functions of memory to recall and re-synthesize in-context information that is already known. Visuals, on the other hand, bypass this process and utilize a more efficient pathway towards understanding, relying on more familiar symbols to convey complex information.

There is thus an ease and universal appeal to visually transmitted information. This may relate to the way we evolved, since human beings learned through observation and imitation before becoming literate (Berge \& Hezewijk, 1999). When discussing learning styles, educators have made distinctions between different types of learners, such as auditory versus visual learners. But researchers are now realizing that the best mode of transmission is 
task dependent, irrespective of someone's learning style (Willingham, 2018). In other words, the task at hand is more important than a client's preference for visual or auditory information. For example, if a client is trying to learn how to delegate, he or she may prefer to listen to a lecture on delegation (auditory) or observe someone who delegates masterfully (visual), yet he or she would benefit from both educational activities. Furthermore, research on learning complex behaviors such as delegation suggests that combining both visual and textual information is optimal (Mayer, 2013; McCrudden \& Rapp, 2017). ${ }^{1}$

So, this brings us back to action-planning in a coaching context. Although there is no database of coaching plans to review, it is our understanding that most action plans today are comprised of predominantly text. The following paper offers coaches an alternative, one that combines visual and textual information.

\section{Polaris: A Promising Visual-Text Hybrid Action Plan}

This paper offers coaches a template to consider using when creating an action plan. We call the template "Polaris", and it is named after the North Star because coaching clients are on a journey. Like travelers on a midnight hike using the stars to navigate, clients need to look up from time to time to make sure they are heading in the right direction. This paper will present a case study that outlines a client's journey using a Polaris, which utilizes both visual and textual information. Then we explain the components of Polaris and cite relevant research that suggests additional potential advantages and benefits of using this tool, beyond ease-of-use and the utility of using both mediums when learning complex behaviors. It is important to do so since the efficacy of visualtext hybrid action plans like Polaris have yet to be examined empirically. ${ }^{2}$ Finally, this paper concludes with recommendations and implications for researchers, coaches, coach supervisors and coach educators.

\footnotetext{
${ }^{1}$ Do the new behaviors that coaching clients typically try to learn qualify as "complex"? Behaviors are considered complex when two criteria are met: (1) the nature of the task has multiple embedded components that comprise the behavior, (2) the client lacks significant experience or knowledge about the task. Under these conditions, the task would be considered complex, and completing it would demand significant mental resources (Hooijdonk \& Krahmer, 2008; Iso-Aholda \& Miller, 2016).

${ }^{2}$ A literature search was conducted using the Web of Science portal with the search words "coaching" "action" "plan" yielding 251 results. The search was further refined to include only social science fields (e.g. psychology, education science, management, etc.) resulting in 70 articles. Within these, no action plan templates are detailed.
} 


\section{Case: "Anne"}

Anne (pseudonym) was the head of a manufacturing division in one of the world's most famous cosmetic companies. When I met her, she had over 1,000 indirect reports and was 6 months into a turnaround job. "Whip this division into shape!" the region's president commanded her. Such a charge did not intimidate Anne, partly because her father was in the military and was quite demanding as a parent. At one point, I asked Anne, "Out of curiosity, what image comes to mind when you think about the challenge before you?" I laid out a few visuals on the table ${ }^{3}$, and was quite surprised when she picked the background image presented in Figure 3.

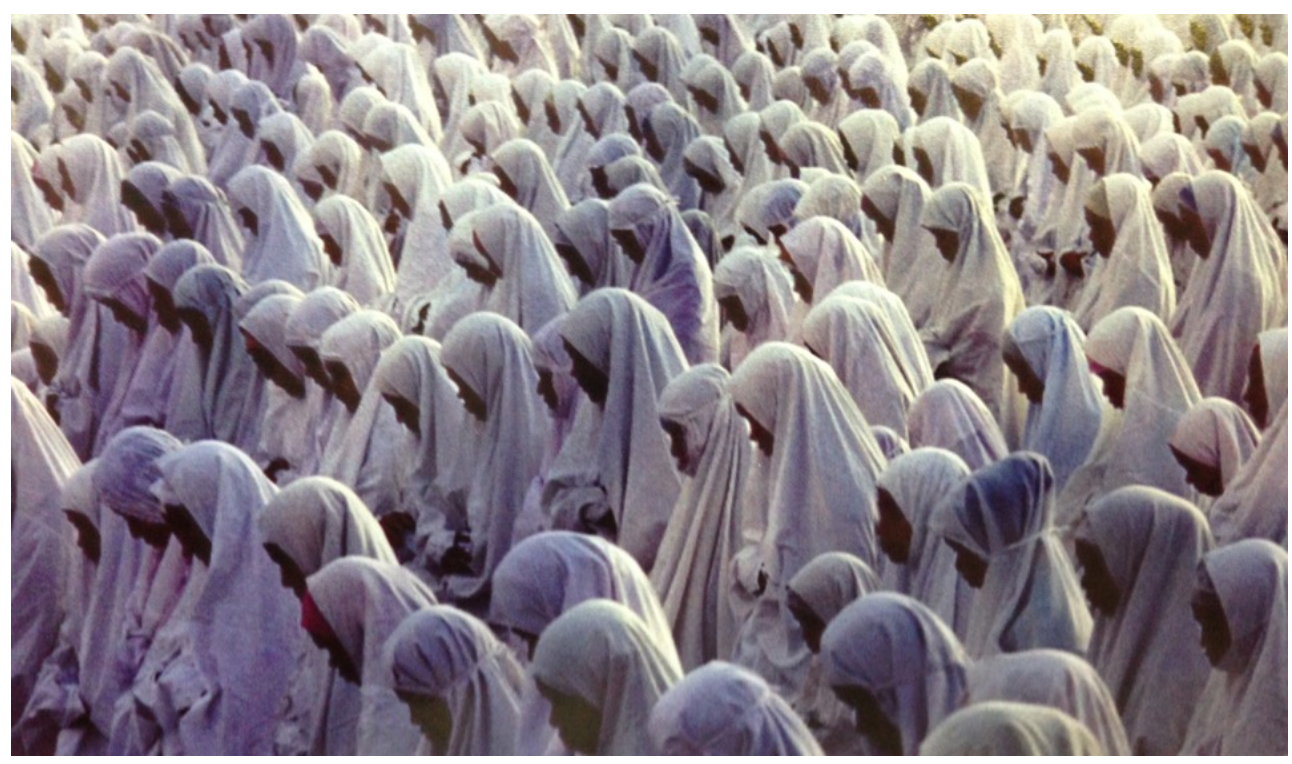

Figure 3. Image picked by client to represent her coaching challenge. From Visual Explorer $^{\mathrm{TM}}$ @ 2019 Center for Creative Leadership. Reproduced with Permission.

Anne didn't strike me as particularly religious, so I asked, "What does this picture mean to you?" Anne smiled and, after a pause, explained that while she's Catholic, what appealed to her about this picture was the unity it conveyed. She needed everyone in the division facing the same direction. As I worked with Anne to accomplish this in the workplace, she made a number of discoveries that she articulated in our sessions.

\footnotetext{
${ }^{3}$ The images displayed were a sampling from Center for Creative Leadership's Visual Explorer $^{\mathrm{TM}}$ tool, an industry standard.
} 
First, Anne realized that the directive behaviors she displayed early in her tenure had some unintended consequences. Namely, people around her became overly dependent on her. They were asking her permission for non-strategic matters, because she had been so critical of what she saw when she came on board. She realized the president was wrong: for this turnaround to succeed, she had to work with and through people - not "whip" them. "How am I going to do that?", Anne wondered out loud. Delegation, patience, and sensitivity were not her strengths, and developing those skills and attributes was a transformative endeavor.

Over time, we identified what Anne needed to do (and not do) on a daily basis. These behaviors are listed as bullet-points in Figure 4. Some of the most difficult work Anne had to do was internal. She had to unlearn entrenched habitual behaviors like "telling." She also had to learn new behaviors, like "exercising silence"-resisting the impulse to rush in and fill conversational gaps. At another moment in her coaching journey, Anne realized that channeling kindness -- both for herself and for others -- was a mindset that helped her listen to others and quiet her criticisms. Finally, another critical step was helping Anne articulate her life's purpose, which she had never done before. The header of the figure below contains a concise version of her purpose. $^{4}$

Overall Anne's transformational journey was non-linear, as is often the case (Boyatzis, 2008). It was a sequence of sincere conversations and numerous meaningful moments that occurred over the course of many months. During this time, we also crafted a written action plan (refer back to Figure 1) and presented that to her supervisor. We complemented this predominantly text action plan with a Polaris (Figure 4), which Anne referred to between coaching sessions. At my suggestion, Anne also authored a letter to her "present self" from her "future self." In other words, I asked her to imagine herself as having accomplished her goal and write down answers to questions such as, "How would achieving this goal feel?" and "What advice would you give your present self from this future vantage point?" Research has found that both effort and persistence increase when individuals conjure positive cognitive representations of what they want to become in the future (i.e., Ruvolo \& Markus, 1992). And

\footnotetext{
${ }^{4}$ I used an inductive process adapted from "The Tree Methodology" created by Pedro Langre. I heard Mr. Langre present it to a corporate audience in New York City on April 30, 2014. Essentially, the process entails having people identify activities that give them joy, and then mining that activity for insights by asking "Why?" five times.
} 
indeed, Anne found authoring this letter helpful and often reread it on her commute home from work.

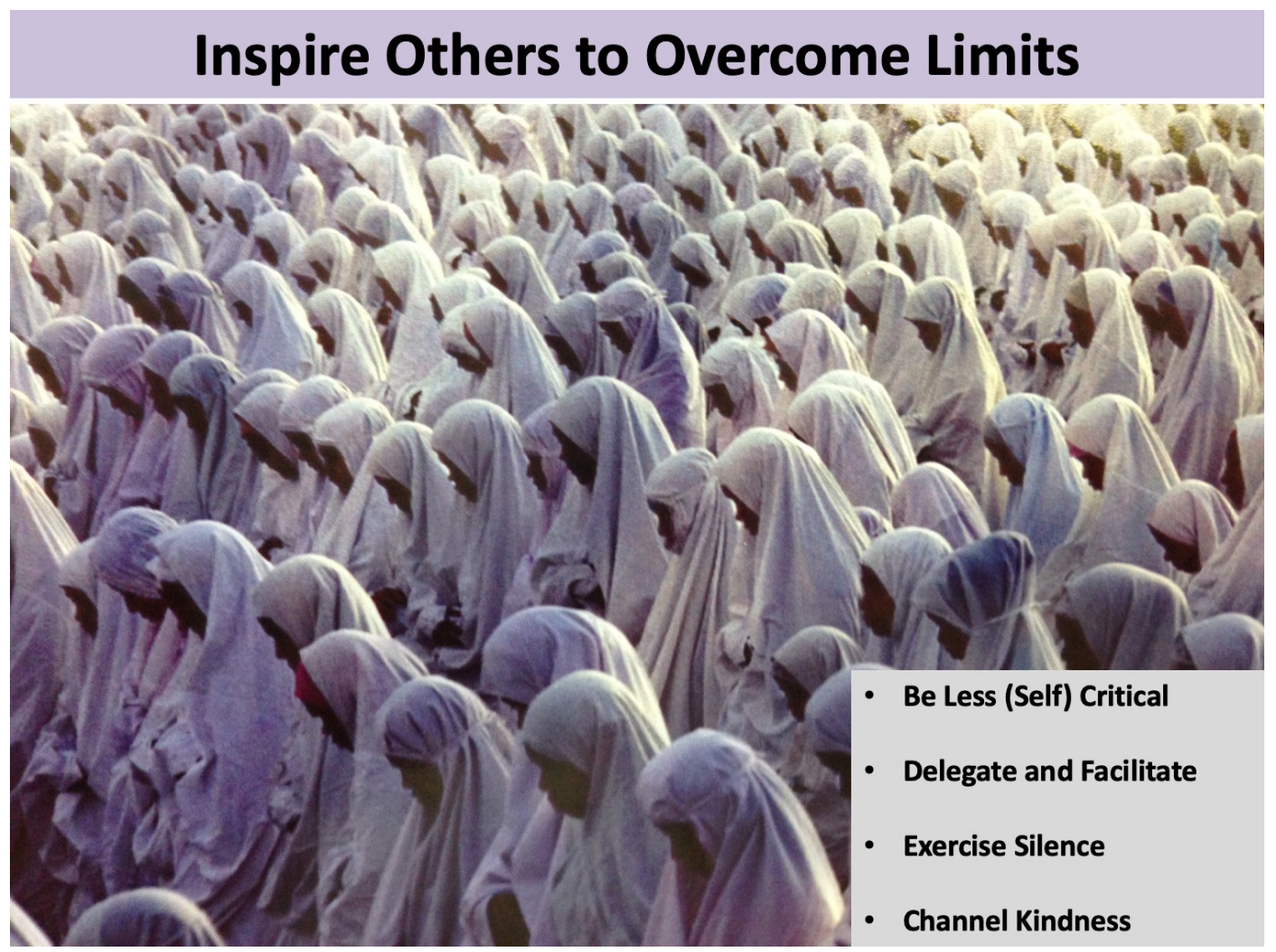

Figure 4: Anne's Polaris

Anne's Polaris was not a "magic bullet." Rather, it was a tool she used in concert with other tools that reflected and supplemented our coaching conversations. Anne's Polaris captured key insights from coaching conversations and converted them into a tangible, easily accessible medium. The visual-text hybrid design of the tool attracted Anne's focus to relevant information and positive feelings that supported her learning and development. In sum, Polaris's visual and textual components came together to create an effective "reminder" and motivational "boost" that helped Anne manage the complex task before her. 


\section{Key Components of the Polaris Template}

The structure of a Polaris includes three primary components (see Figure 5). The headline concisely captures the client's overall purpose. Below the headline are three to five "cognitive reminders" - short bullet points that identify key behaviors, values, or phrases that are meaningful to the client's goal pursuit. The reader will note that bullet points are also utilized in text-only action plans, so the two action planning templates overlap in this regard. For the third, and most unique component, the client chooses an image that relates to the coaching challenge and which ideally stimulates positive emotions (i.e., inspiration, excitement). The three components will be co-created by the coach and the client using themes that emerge from coaching conversations. Thus, the Polaris will be client-centric and personally relevant to the client's agenda. The following section explains the rationale behind the components (i.e., Why bullet point reminders? Why stimulate positive emotions?) citing extant literature from fields of education, persuasion science, and motivational psychology.

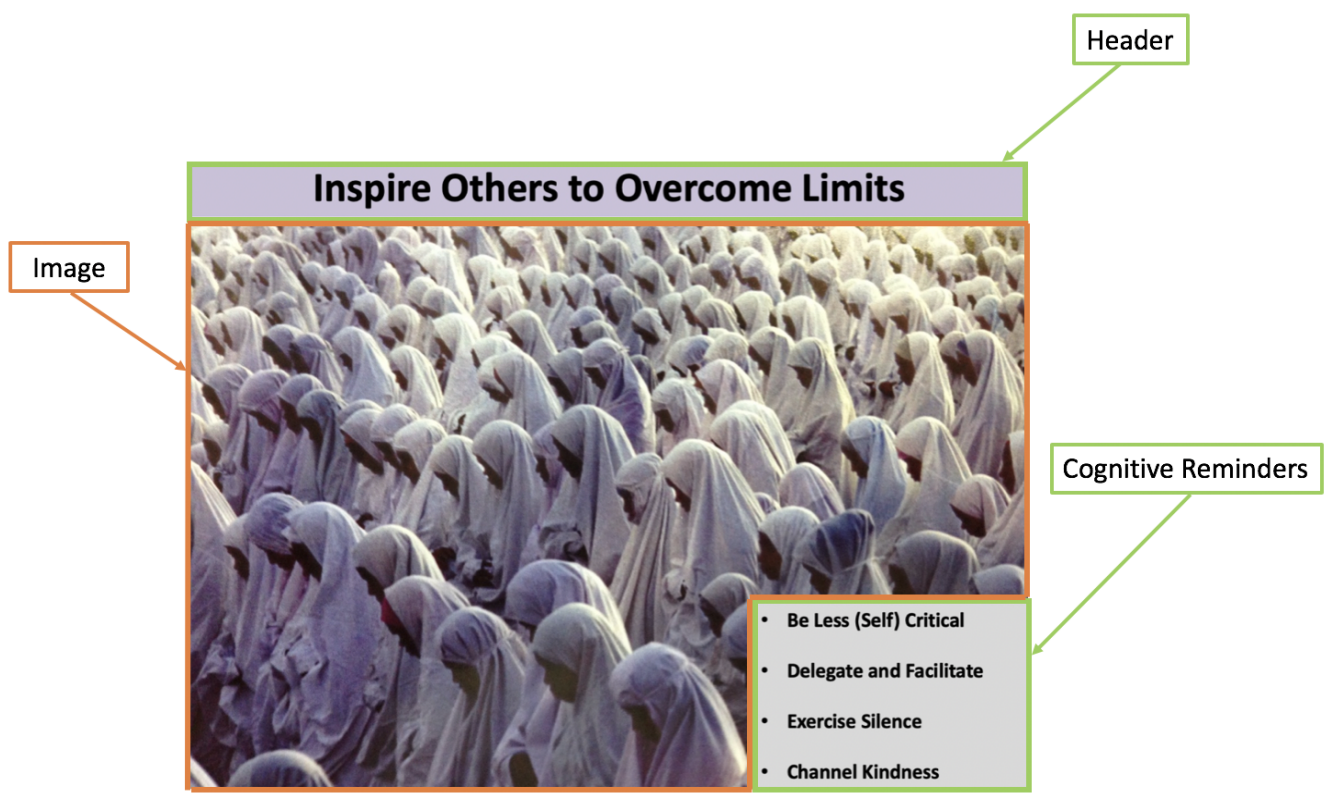

Figure 5: The three components of Polaris 


\section{What Evidence Supports the Polaris Approach?}

\section{The "Whole-Person" Approach: Engaging the Head and the Heart}

Overall this paper posits that a text-visual hybrid action plan reflects a "Whole-Person" approach to learning (Yorks \& Kasl, 2002), appealing to both the head and the heart of a coaching client. Why might many coaching action plans today exist in a predominantly text format? This may be due to the fact that organizations often reward and privilege "thinking" as the prime way of knowing (Brydon-Miller \& Coghlan, 2014; Walsh, 1995). Alternatively, visualtext hybrids appeal more to "presentational knowledge" - that is, knowing the essence of something by displaying it in imaginative form. Doing so reveals underlying patterns (Heron, 1992), and provides for what some researchers call a "more sensuous encounter" (Seeley \& Reason, 2008). Tapping into the sensory system - the one accessed primarily through visuals - may unleash additional motivation, as will now be discussed.

There is evidence that the process of creating text-visual hybrids benefits people on multiple levels. One recent study contrasted the impact of authoring a text-based written paper with creating a visually rich infographic (Stoerger, 2018). The process of creating the infographic helped learners analyze and synthesize complex information in a variety of ways, which generated a greater sense of pride and accomplishment relative to authoring a paper. This is consistent with studies that demonstrate how the process of synthesizing complex information into accessible infographics enables learners to not only understand, but appreciate that information (Lindblom, Galante, Grabow, \& Wilson, 2016). In a coaching context, coaches often work with leaders whose time is limited. So, asking leaders to author both a text-heavy action plan (i.e., Figure 1) and asking them to create a text-visual hybrid like Polaris (i.e., Figure 4) may feel like a risky proposition. Coaches may feel pressure to pick one versus the other. However, it has been our experience that both activities create value for clients. Both text-only and visual-text hybrid action plans help viewers focus their cognition on the most relevant information. The difference is that the text symbol system is abstract and linguistic, while the picture symbol system is sensory (Hooijdonk \& Kramer, 2008). Again, research suggests that tapping into the sensory system may help clients comprehend and appreciate the value of their behavior change. Thus, it is the position of this paper that complex behavior is learned best when the abstract, linguistic, and sensory systems are all activated. We now turn our attention to research from the field of advertising, which illustrates the power of visual images to influence a different aspect of the "Whole-Person": one's body. 


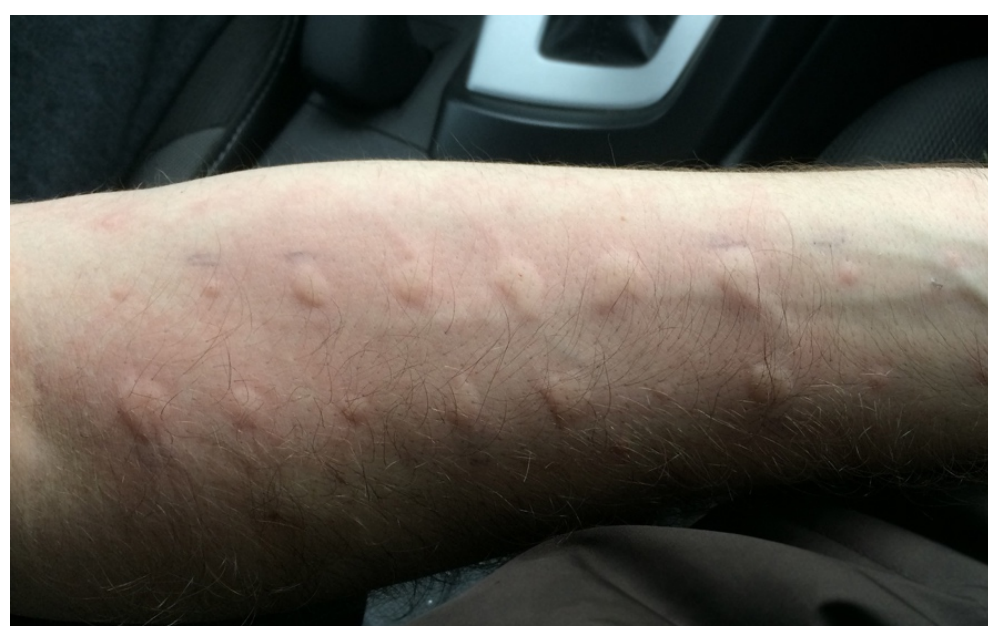

Figure 6: Photograph of wheal reactions resulting from a histamine challenge allergen test. Digital Photo from Adobe Stock.

\section{Advertising: It's All in Your Head (and Body)}

Research has demonstrated the power that mindset has on driving behavior change (Adams, 2015; Dweck, 2012). The placebo effect in medicine, for example, has been proven to have real, measurable benefits due to its impact on mindset: beliefs about the quality of a drug can impact the drug's efficacy. Furthermore, research also demonstrates the strong influence that images have on both our beliefs and our bodies. Take the following randomized clinical trial conducted by researchers at the University of Chicago (Kamenica, Naclerio, \& Malani, 2013). Researchers asked: is it possible to significantly affect the physiological impact of an allergy drug through advertising?

The answer is yes! Advertisements significantly influenced the speed and degree to which an induced allergic reaction diminished in the experimental trial comparison of two allergy drugs. Participants who were shown negative advertising about the drug they took healed slower than people who saw positive ads.

In the study, participants received a well-established common allergen skin test known as a histamine challenge, which triggers a response called a wheal reaction - a slightly reddened, elevated area at the challenge site (see Figure 6). Participants were all given $10 \mathrm{mg}$ of an antihistamine drug called Claritin and explicitly made aware of the Claritin brand. A pre-test was conducted to measure participants' subjective beliefs about the efficacy of the 
drug they would be taking in addition to initial measures of the wheal reaction. All participants watched a movie with naturally-timed advertisement breaks, but participants were randomly assigned to two experimental conditions to test whether the variance in the advertisement information about allergy drugs made a difference in healing.

Condition 1 participants saw a Claritin advertisement in each break whereas Condition 2 participants saw an advertisement for one of the drug's main competitors, Zyrtec. Participants knew they took Claritin to soothe the wheal reaction. The Zyrtec commercials claimed that Zyrtec works faster than Claritin. Visual exposure to the Zyrtec commercial, which challenged the effectiveness of the Claritin drug participants had taken, was powerful enough to slow down the healing process for those individuals. The results were supported by a series of repeated wheal measurements at multiple intervals, and a post-test evaluation was conducted to measure participants' belief about the efficacy of Claritin at the end of the study.

This allergy study demonstrates the ability of information conveyed in a hybrid text-plus-visual format to affect the mind (and body). Granted, the advertisements in this study are "moving pictures," while Polaris is a static image. But studies involving photographs (e.g., Shantz \& Latham, 2009) have also found that static images affect viewers in profound ways, including acting upon their motivations. Secondly, this study's physiological data suggests that the mind can influence the body when persuaded. But how does one get persuaded? Might Polaris also serve a persuasion function? Consider the following interesting research findings from the realms of persuasion science and motivational psychology.

\section{Persuasion Science and Motivational Psychology: Transport your Clients}

What image comes to mind when you think of coaching? Laypeople often think of sports coaches. The noun "coach" actually refers to a stagecoach, a vehicle used as early as the 16th century to transport people (see Figure 7). Likewise, coaching as a profession is often conceived as transporting people from where they are to where they want to be (Maltbia, 2010). 


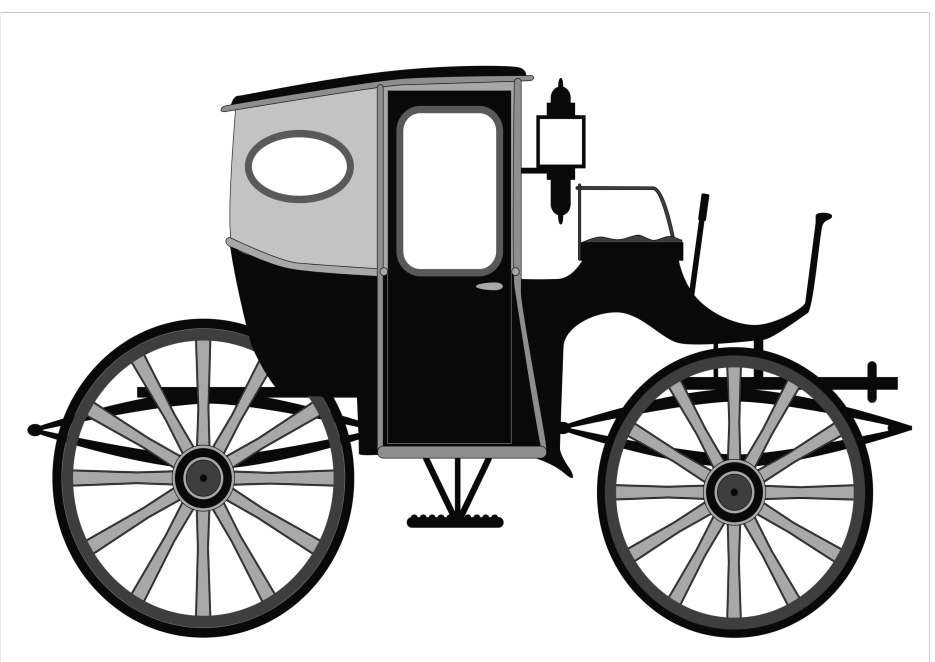

Figure 7: "A stagecoach is a vehicle to physically transport people. A coach is a professional that metaphorically transports people from where they are to where they want to be." Digital Photo from Adobe Stock.

Interestingly, "transportation" is also an important concept in persuasion science. Transportation in this field refers to a phenomenon that occurs when a reader gets caught up in a story. The reader temporarily loses him or herself and experiences a feeling of entering a new world. He or she is thus transported by the narrative. This feeling is evoked, according to theorists, by the reader's empathy for the characters as well as by the imagination inherent to the story's plot (O'Keefe, 2016). In other words, to be persuaded, people need to relate in some way to a story's characters and experience a sense of engagement in what's happening to these characters. It turns out that persuasion isn't purely logical. It contains an emotional, sensory component as well.

To cross the "gap" between where they are and where they want to be, coaching clients need to be persuaded that such a journey is possible. Tapping into a client's imagination and feelings may be important for clients to persuade themselves. Indeed, self-efficacy - an individual's belief in their ability to achieve goals - is a key psychological variable of coaching effectiveness (Bozer \& Jones, 2018) and may be increased via verbal persuasion and emotional arousal (Bandura, 1982).

Recent research on guided visualization - a sensory experience where people are transported by listening to verbal, pre-recorded scripts - supports the notion that people's beliefs may be manipulated and shows why (Rawolle, Schulthesiss, Strasser, \& Kehr, 2017). A research team from the Technical 
University of Munich asked participants to lay down on a couch and listen via headphones to a guided visualization (see Figure 8). Participants were asked to close their eyes and imagine the described scenario vividly, just as if they were dreaming it.

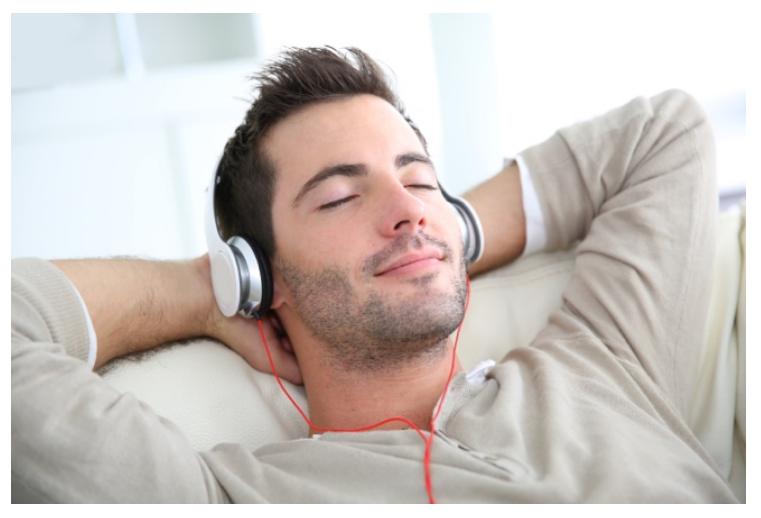

Figure 8: Participants were asked to lay down and listen via headphones to a prerecorded script. Digital Photo from Adobe Stock.

The researchers manipulated numerous variables, and their findings support our thesis in a number of ways. First, they determined that the mental picture-like images generated by the exercise enhanced participant's beliefs that their desired goal could be achieved. Conjuring an image of a successful endstate made the destination seem real and possible, whereas previously it may have been more of a theoretical or abstract possibility. Polaris operates in a similar manner. Identifying the purpose statement (the headline component) and the necessary short-term behaviors (the cognitive reminders component) makes the client's destination appear more real and possible.

Furthermore, researchers found evidence that visionary images energize and aid participants in taking actions instrumental to their goals. In one of their studies, participants performed better on a mental concentration task after a 7minute guided visualization; in another they exhibited more cooperative behaviors (Rawolle et al., 2017). Regardless of the actions taken, for motivation to be activated the following criteria had to be met: the visuals people imagined needed to be (1) picture-like, (2) identity-relevant, (3) positive, and (4) reflective of a long-term perspective.

Although the researchers were using verbalized words to conjure an image, similar effects are likely to be generated by Polaris, which utilizes an actual image. This is because an actual image chosen by the client (the third 
component of Polaris) will arguably be more identity-relevant and yield more positive feelings and motivation than visualizations written and read by someone else. When there is a personal vision tied to the client's chosen image, research demonstrates that this connection activates neural mechanisms that motivate the client and move him or her to tackle difficulties, which also helps the client open up to new ideas (Boyatzis \& Jack, 2018). Polaris also moves beyond being "picture-like" into using an actual picture, which likely creates an even more sensuous encounter. Regardless, Polaris's components and usage strongly align with the four criteria identified above.

It is important to note another finding by the guided visualization research team. They found visual imagery to be an effective way to access a person's unconscious or implicit motivation. This is because the implicit motivation system responds better to pictorial, non-verbal stimulus. A goal written in a language-based, written-word format appeals more to one's conscious or explicit motivation system. Interestingly, the researchers found evidence that visual imagery may generate greater congruence of both motivational systems (i.e., implicit and explicit). So, once again we have a line of research which suggests that Polaris appeals to the "Whole Person" more effectively relative to action plans that are predominantly text. Although written words may generate an arousing mental image if they are structured in a narrative, transporting format, action plans are not typically crafted in such a manner.

\section{Polaris is a "Living Document"}

Action plans, whether text-heavy or a visual-textual hybrid, need to evolve over time. Goals are not static (Clutterbuck \& Spence, 2017), and an effective action plan needs to reflect this dynamic nature. Polaris is like a photograph that captures the culmination of reflective coaching conversations conducted up to that moment in time. As the client gains additional insight about how to accomplish his or her goal, the cognitive reminders of the tool should be updated. Similarly, the image can also be "refreshed" to maintain its positive motivational power. The purpose statement at the top of the tool is the least likely of the three components to change, as "big-picture" goals are relatively more stable than the operational goals that support them (Scheier \& Carver, 1980).

Given these dynamics, when should Polaris be deployed? Polaris plays an integral role in every phase of goal pursuit: the antecedents phase, the integration phase, and the maintenance phase (Berkman \& Rock, 2014). The antecedents phase involves determining which goals to pursue and linking this 
goal to a person's enduring sense of who they are. The purpose statement located at Polaris's header accomplishes this task explicitly. The integration phase links abstract, long-term goals (the "why") with concrete, short-term actions (the "how"). Polaris's bullet-point, cognitive reminders accomplish this task explicitly as well. The final phase of goal pursuit is the maintenance phase, which involves solidifying and automating new behaviors that have emerged. Automation (habit-formation) involves identifying and pairing cues with goals. For example, leaving the office to go home at the end of the day was Anne's cue to reflect on her goal. She did this every day, and after some time, the habit became automatic. Similarly, the Polaris tool itself can act as a cue if it is placed in a visible location for a client to encounter. For this reason, our coaching clients save their individual Polaris, typically created as a Microsoft Powerpoint slide, as a JPG file and place it as a desktop or mobile wallpaper.

\section{Conclusion: Putting it All Together}

Goal pursuit is often challenging and involves non-linear progress. This paper questions the use of "cold" action plans (i.e., text-heavy, abstract) with clients, when a coach could use "hot" plans (i.e., visual-text hybrid, inspiring) that activate client focus and motivation for a more successful goal-attainment journey. As Berkman and Rock (2014) note:

\section{One final "hot" element that has been missing from models of goal setting to date is "stickiness," or how to set goals that will always be at the front of your mind and on the tip of your tongue. Stickiness is important because people are busy and have only limited attentional resources - a goal that does not stick firmly in mind can easily be washed away in the tidal wave of other priorities and distractions. (p. 4)}

There are reasons to think that goals captured by a Polaris will be more successful at remaining on the tip of clients' tongues relative to text-heavy plans. To summarize, visual-text hybrid action plans:

- Convey information in a more accessible format, one that utilizes quicker visual processing mechanisms. The speed and ease in which one could use the visual-text hybrid action plans are likely appreciated by clients operating in today's modern, fast-paced, distraction-filled workplace.

- Are an optimal medium to transmit information to clients trying to learn complex behaviors. This paper theorizes that complex behaviors are learned best when the "Whole-Person" is engaged - meaning that 
the abstract, linguistic, and sensory systems of the person are all activated.

- May lead to better goal attainment due to engagement of coaching clients' beliefs via emotional and sensory processes. Building a tool like Polaris with clients likely builds their self-efficacy, arouses explicit and implicit motivation, and catalyzes instrumental actions. It may also transport clients more effectively than textual information alone.

- Are most likely to be effective if coaches ensure that the plan is identity-relevant, positive, and reflective of a long-term perspective.

Overall, a visual-text hybrid tool like Polaris may help clients not only comprehend the upcoming changes required of them, but also appreciate the value of this pursuit. Perhaps most importantly, Polaris helps clients persuade themselves that their behavior change is necessary and possible. Through the emotionally evocative and transporting power of the visual imagery, clients are reminded that change is within their grasp, if only they choose to follow this guiding light.

\section{Limitations and Future Research}

Additional research is needed to test this paper's thesis. While there is research from various fields supporting the visual-text hybrid nature of the Polaris template, a randomized control trial would verify whether visual-text hybrid action plans result in statistically significant gains in client goal attainment compared to action plans that are predominantly text. How much might Polaris actually "speed up" the goal attainment process for clients? That too would be useful information, particularly for coaches debating whether to supplement or supplant a traditional text-based plans with a visual-text hybrid.

Future research should also examine causal relationships underlying the mechanisms hypothesized in this paper. Does Polaris transport clients and arouse implicit motivations more effectively than text-heavy action plans? What happens to a client's motivation when one or more of Polaris's components are missing, introduced in different order sequences, or if one of the guidelines are violated (i.e., it does not reflect a long-term perspective)?

Another important unanswered question is: how often should a client refer to his or her action plan? This paper made the case that Polaris plans are more easily accessible than plans that are predominantly text. However, it is not clear how often either format should be reviewed. In the case study presented, 
the coaching client actively viewed her Polaris on a daily basis for a number of months. This was successful in this case, however, are there individual differences here, or might this frequency generalize to the coaching client population writ large? Researchers may compare the longitudinal impact of daily viewing for three months, for example, versus less frequent viewing. This also raises the question of what happens if a coaching client views their Polaris in a "passive" manner? In other words, over time a publicly displayed Polaris (i.e., above a worker's desk) may in effect become wallpaper. How fast do the viewing effects of Polaris diminish? Research can help determine how often an image should be "refreshed" to maintain its motivational effects. Interestingly, recent studies on so-called "open label placebos" - placebo pills honestly prescribed to patients without deception - suggest that the act of taking the pill is actually more important than what the patient thinks (Kaptchuk, 2018). If true, the embodied act of referring to an action plan may prove to be more instrumental to client development than coaches currently realize.

\section{Implications for Practice}

In addition to suggesting an agenda for future coaching research, this paper also has several practical implications for practitioners, including coaching supervisors and educators.

\section{Coaches and Clients}

By following the example and guidelines articulated in this paper, coaches will now be able to co-create a Polaris with their clients. Once created, both coaches and clients will have access to a product which reflects their work in an easy-to-access, visual-text format. Essentially, key moments in the client's journey will be captured and transformed into a tangible aid. Given the absence of research on visual-text hybrid action plans in a coaching context, we encourage both coaches and clients to experiment with Polaris to determine for themselves whether the approach yields motivational benefits and supports behavioral change. Tactically, coaches may also experiment with referring to a client's Polaris between sessions. For example, coaches can refer to the visual image when preparing for a coaching call. Might this be a more efficient and effective method of preparation relative to only reading text-based sessions notes? 


\section{Coaching Supervisors}

Supervision is emerging as a fundamental aspect of continuing professional development for coaches (Hawkins, 2018). It is a space where coaches can reflect on particular client situations and relationships, as well as the reactivity and patterns they evoke. In this context, coach supervisors may encourage coaches to share a client's Polaris when discussing a case. The visual-text medium may be a more efficient and effective way to discuss coaching cases relative to an oral or written presentation. Given that learning and refining coaching skills is arguably a complex endeavor, a hybrid approach to this task may be optimal. Overall, it is important to discover if discussing cases in different mediums (or a combination of mediums) yields superior insights and results for coaches and clients. Supervisors may also seek to determine if Polaris supports the three functions of supervision equally (Hawkins \& Smith, 2013). Namely, do visual-text hybrid action plans for coaches support the resourcing, developmental and qualitative functions to the same extent? Interestingly, there are already calls for using metaphors and small objects in coaching supervision as an adjunct to talking, due in part to results garnered from sandplay counseling methods (Seto \& Geithner, 2018; Russo, Vernam, and Wolbert, 2006).

A second application of Polaris would be for supervisors to create a visual-text hybrid with their coaches as a way to capture and synthesize the coach's current state of development (as opposed to the client's state of development). The authors offer an example Polaris in Figure 9 where the coach is the focus. This Polaris was crafted by one of the authors and shared with his coach supervisor to aid reflective dialogue about the extent to which he was able to live up to his ideal future self-as-coach.

As the reader will note, the coach's purpose is articulated in the headline of Figure 9 ("Catalyze Growth"), and three cognitive reminders are listed in bullet-point format to support the coach's ongoing development. The image chosen by the coach was identity-relevant and generated positive affect, per the guidelines offered previously. In fact, it was a photograph of a painting drawn by one of his coaching clients who wanted to reconnect with her artistic self as an outlet to deal with workplace stress. And as her coach, the author found it personally meaningful that she succeeded in actualizing this generative act. The author saw it as "evidence" that he was living his purpose as a coach. 


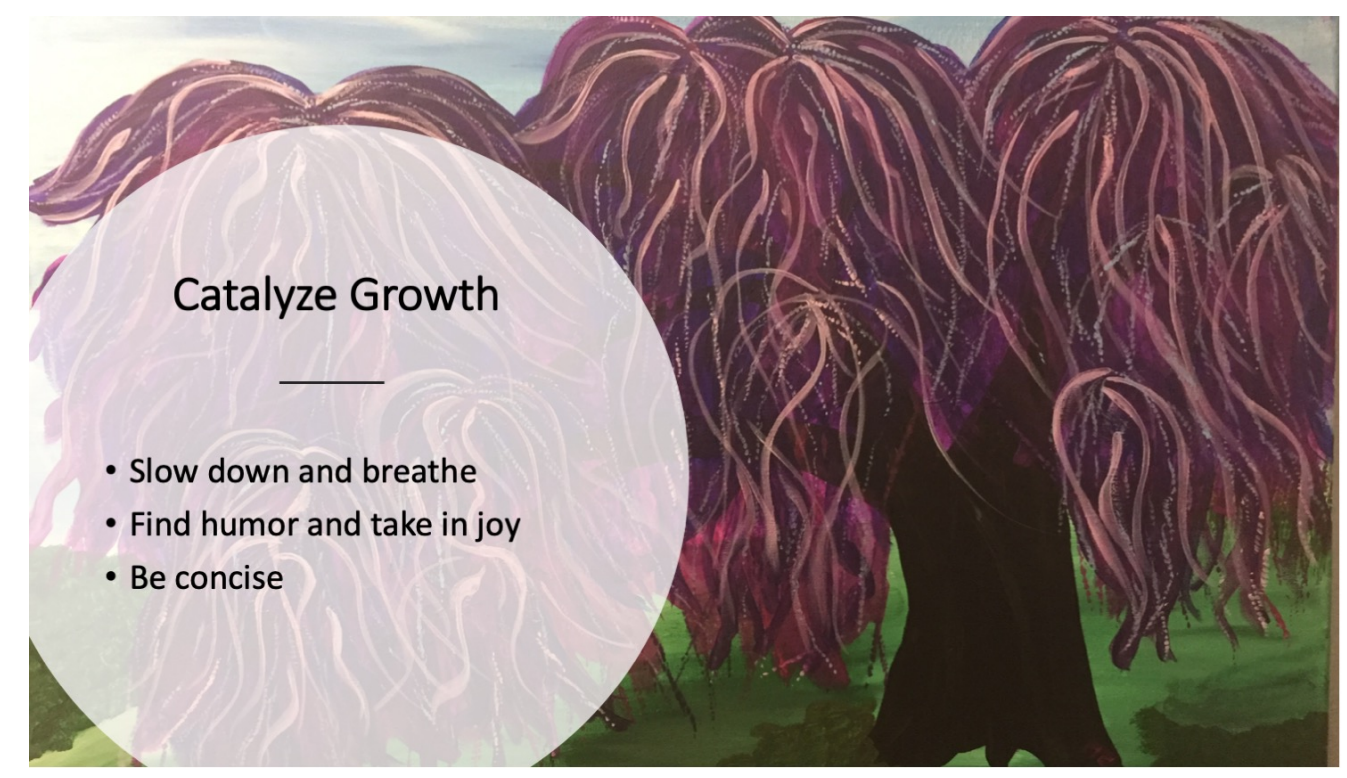

Figure 9: An example Polaris created by a coach (one of the authors) and shared with his coach supervisor to facilitate developmental dialogue.

\section{Coach Educators, Trainers and Developers}

Those educating, training, and developing coaches may also explore how to utilize visual-text hybrid plans as part of their process. The current state of play in coach education, training, and development is quite varied, with providers relying on a range of learning theories and formats (Gannon \& Mayers, 2018). For example, some providers offer short, non-certificate coaching courses to introduce essential coaching skills, while other providers, such as universities, offer more formal coach education that equips students with a strong theoretical orientation to unpin their practice. Each provider may be attracted to different aspects of Polaris. Trainers deploying instrumental learning theories (Skinner, 1954) may appreciate Polaris' focus on three cognitive reminders. Educators deploying a constructivism approach (Piaget, 1952) would likely appreciate that the very act of creating a Polaris is an experience that helps organize and build upon the students' existing learning. Might students learn coaching skills faster if they create a Polaris for themselves? Evaluation research would need to examine that possibility empirically.

In sum, there may be differences when deploying Polaris in different contexts with different populations (i.e., leaders learning to adapt their skills to 
a new organizational context, experienced coaches refining their skills, students learning coaching skills for the first time). Yet in all cases, Polaris will likely appeal to the "Whole Person" by activating the abstract, linguistic, and sensory systems of the learner. Until empirical research is conducted in these various contexts, the potential fruits of this endeavor remain an unverified theoretical proposition. However, it is the authors' experience that Polaris can be a more powerful instigator of positive change and the attainment of client-centric, valued goals. It is our hope that, like the North Star, the text-visual hybrid of Polaris as a coaching tool can help ensure clients have a clear, visual guide to achieve their goals.

\section{References}

Adams, M. (2015). Change your questions, change your life: 12 powerful tools for leadership, coaching, and life. Oakland, CA: Berrett-Koehler.

Bandura, A. (1982). The psychology of chance encounters and life paths. American Psychologist, 37(7), 747-755. doi:10.1037/0003066x.37.7.747

Berge, T.T. \& Hezewijk, R.V. (1999). Procedural and declarative knowledge: An evolutionary perspective. Theory \& Psychology, 9(5), 605-624. doi:10.1177/0959354399095002

Berkman, E. \& Rock, D. (2014). AIM: An integrative model of goal pursuit. NeuroLeadership Journal, 5, 1-11. Retrieved from https://membership.neuroleadership.com/neuroleadership-journal/

Boyatzis, R.E. \& Saatcioglu, A. (2008). A 20-year view of trying to develop emotional, social and cognitive intelligence competencies in graduate management education. Journal of Management Development, 27(1), 92-108. doi:10.1108/02621710810840785

Boyatzis, R.E. \& Jack, A.I. (2018). The neuroscience of coaching. Consulting Psychology Journal: Practice and Research, 70(1), 11-27. doi:10.1037/cpb0000095

Bozer, G. Jones, R.J. (2018). Understanding the factors that determine workplace coaching effectiveness: a systematic literature review. European Journal of Work and Organizational Psychology, 27(3), 342361. doi:10.1080/1359432x.2018.1446946

Clutterbuck, D.A. \& Spence, G. (2017). Working with goals in coaching. The Sage Handbook of Coaching. Thousand Oaks, CA: SAGE.

Brydon-Miller, M. \& Coghlan, D. (2014). The big picture: Implications and imperatives for the action research community from the SAGE 
encyclopedia of action research. Action Research, 12(2), 224-233. doi: $10.1177 / 1476750314533135$

Dweck, C.S. (2012). Mindset The New Psychology of Success: How We Can Learn to Fulfill our Potential. New York, NY: Random House.

Freitas, V. (2019). Person Eye. [Digital Photograph]. Retrieved from https://www.pexels.com/photo/person-eye-865711/

Gannon, J. \& Myers, A. (2018). Coach Education, Training and Development. The Complete Handbook of Coaching. Thousand Oaks, CA: Sage.

Hagen, S. (2002, March). The mind's eye. Rochester Review, 74(4), 32-37. Retrieved from https://www.rochester.edu/pr/

Hawkins, P. (2018). Coaching Supervision. The Complete Handbook of Coaching. Thousand Oaks, CA: Sage.

Hawkins, P. \& Smith, N. (2013). Coaching, mentoring, and organizational consultancy: Supervision, skills \& development (2nd Ed.). Berkshire, England: Open University Press.

Heron, J. (1992). Feeling and personhood: Psychology in another key. London: Sage.

Hives on an arm, the results of an allergy needle prick test. [Online digital image]. (n.d.). Retrieved April 19, 2019 from https://stock.adobe.com/search?k=allergen\%20bump\&asset_id=239862 724

Hooijdonk, C.V. \& Krahmer, E. (2008). Information modalities for procedural instructions: The influence of text, pictures, and film clips on learning and executing RSI exercises. IEEE Transactions on Professional Communication, 51(1), 50-63. doi:10.1109/tpc.2007.2000054

Iso-Ahola, S.E. \& Miller, M.W. (2016). Contextual priming of a complex behavior: Exercise. Psychology of Consciousness: Theory, Research, and Practice, 3(3), 258-269. doi:10.1037/cns0000078

Kamenica, E., Naclerio, R., \& Malani, A. (2013). Advertisements impact the physiological efficacy of a branded drug. Proceedings of the National Academy of Sciences, 110(32), 12931-12935. doi:10.1073/pnas.1012818110

Kaptchuk, T.J. (2018). Open-label placebo: Reflections on a research agenda. Perspectives in Biology and Medicine, 61(3), 311-334. doi:10.1353/pbm.2018.0045

Lindblom, K., Galante, N., Grabow, S., \& Wilson, B. (2016). Composing infographics to synthesize informational and literary texts. English Journal, 105(6), 37-45. Retrieved from http://www2.ncte.org/resources/journals/english-journal/ 
Maltbia, T.E. (2010). Academic festival 2010 leadership effectiveness: The Columbia coaching certification program [Powerpoint Slides].

Retrieved from https://www.slideshare.net/Temaltbia/academic-festivalexecutive-leadership-coaching-guest-v1

Mayer, R. \& Gallini, J. (1990). When is an illustration worth ten thousand words? Journal of Educational Psychology, 82(4), 715-726. doi:10.1037/0022-0663.82.4.715

Mayer, R.E. (2013). Fostering learning with visual displays. In G. Schraw, M.T. McCrudden, \& D. Robinson (Eds.), Learning through visual displays (pp. 47-73). Charlotte, NC: Information Age Publishing.

McCrudden, M.T. \& Rapp, D.N. (2017). How visual displays affect cognitive processing. Educational Psychology Review, 29, 623-639. doi:10.1007/s10648-015-9342-2

O'Keefe, D. J. (2016). Persuasion: Theory and Research (3rd Ed.). Thousand Oaks, CA: Sage.

Old Style Carriage. [Online digital graphic]. (n.d.). Retrieved April 19, 2019 from https://stock.adobe.com/images/old-stylecarriage/93322997?prev_url=detail

Piaget, J. (1952). The origins of intelligence in children. New York, NY: International Universities Press.

Rawolle, M., Schultheiss, O. C., Strasser, A., \& Kehr, H. M. (2017). The motivating power of visionary images: Effects on motivation, affect, and behavior. Journal of Personality, 85(6), 769-781. doi:10.1111/jopy.12285

Russo, M.F., Vernam, J., \& Wolbert, A. (2006). Sandplay and storytelling: Social constructivism and cognitive development in child counseling. The Arts in Psychotherapy, 33(3), 229-237. doi:10.1016/j.aip.2006.02.005

Ruvolo, A.P. \& Markus, H.R. (1992). Possible selves and performance: The power of self-relevant imagery. Social Cognition, 10(1), 95-124. doi:10.1521/soco.1992.10.1.95

Scheier, M.F. \& Carver, C.S. (1980). Private and public self-attention, resistance to change, and dissonance reduction. Journal of Personality and Social Psychology, 39(3), 390-405. doi:10.1037/00223514.39.3.390

Seeley, C., \& Reason, P. (2008). Expressions of energy: An epistemology of presentational knowing. In P. Liamputtong \& J. Rumbold (Eds.), Knowing differently: Arts-based and collaborative research (pp. 25-46). New York, NY: Nova Science. 
Seto, L. \& Geithner, T. (2018). Metaphor magic in coaching and coaching supervision. International Journal of Evidence Based Coaching and Mentoring, 16(2), 99-111. doi:10.24384/000562

Shantz, A. \& Latham, G.P. (2009). An exploratory field experiment on the effect of subconscious and conscious goals on employee performance. Organizational Behavior and Human Decision Processes, 109(1), 9-17. doi:10.1016/j.obhdp.2009.01.001

Skinner, B.F. (1954). The science of learning and the art of teaching. Cambridge, MA: Harvard University Press.

Stoerger, S. (2018). Writing without words: Designing for a visual learning experience. Education for Information, 34(1), 7-13. doi:10.3233/efi189002

Thorpe, S.J., Fize, J., \& Marlot, C. (1996). Speed of processing in the human visual system. Nature, 381, 520-522. doi:10.1038/381520a0

Walsh, J. P. (1995). Managerial and organizational cognition: Notes from a trip down memory lane. Organization Science, 6(3), 280-321. doi:10.1287/orsc.6.3.280

Willingham, D.T. (2018). Unlocking the science of how kids think: A new proposal for reforming teacher education. Education Next, 18(3), 42-49. Retrieved from https://www.educationnext.org/journal/

Yorks, L. \& Kasl, E. (2002). Toward a theory and practice for whole-person learning: Reconceptualizing experience and the role of affect. Adult Education Quarterly, 52(3), 176-192. doi: $10.1177 / 0741713602052003002$

Young man listening to music with headphones. [Online digital image]. (n.d.). Retrieved April 19, 2019 from https://stock.adobe.com/Library/f6276e6c-2cd4-4792-b5b0 4952ae2311c2?asset_id=59547349

\section{Author Contact}

Correspondence concerning this article should be addressed to Yaron Prywes. E-mail:yp2002@tc.columbia.edu 